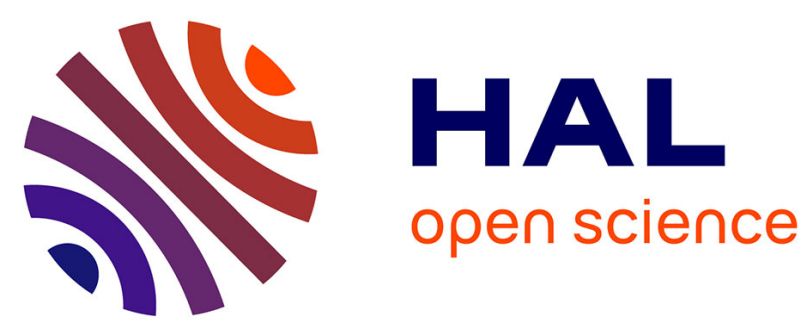

\title{
Modeling the deformation textures and microstructural evolutions of a Fe-Mn-C TWIP steel during tensile and shear testing
}

David Barbier, Véronique Favier, Bernard Bolle

\section{- To cite this version:}

David Barbier, Véronique Favier, Bernard Bolle. Modeling the deformation textures and microstructural evolutions of a $\mathrm{Fe}-\mathrm{Mn}-\mathrm{C}$ TWIP steel during tensile and shear testing. Materials Science and Engineering A- Structural Materials Properties Microstructure and Processing, 2012, 540, pp.212-225. 10.1016/j.msea.2012.01.128 . hal-02537150

\author{
HAL Id: hal-02537150 \\ https://hal.science/hal-02537150
}

Submitted on 8 Apr 2020

HAL is a multi-disciplinary open access archive for the deposit and dissemination of scientific research documents, whether they are published or not. The documents may come from teaching and research institutions in France or abroad, or from public or private research centers.
L'archive ouverte pluridisciplinaire HAL, est destinée au dépôt et à la diffusion de documents scientifiques de niveau recherche, publiés ou non, émanant des établissements d'enseignement et de recherche français ou étrangers, des laboratoires publics ou privés. 


\title{
Modeling the deformation textures and microstructural evolutions of a Fe-Mn-C TWIP steel during tensile and shear testing
}

\author{
D. Barbier ${ }^{\mathrm{a}, *}$, V. Favier $^{\mathrm{b}}$, B. Bolle $^{\mathrm{c}}$ \\ a ArcelorMittal Research, Voie Romaine-BP30320, 57283 Maizières-lès-Metz Cedex, France \\ ${ }^{\mathrm{b}}$ Arts et Metiers ParisTech, PIMM UMR CNRS 8006, 151 Bd de l'Hôpital 75013 Paris, France \\ c LEM3 UMR CNRS 7239, Ecole Nationale d'Ingénieurs de Metz, F-57078 Metz Cedex 3, France
}

\section{Keywords:}

TWIP steel

Micromechanical mode

Tensile and shear deformation

Texture and microstructure evolutions

\begin{abstract}
A B S T R A C T
The high manganese austenitic steels with low stacking fault energy (SFE) present outstanding mechanical properties due to the occurrence of two strain mechanisms: dislocation glide and twinning. Both mechanisms are anisotropic. In this paper, we analyzed the effect of monotonous loading path on the texture, the deformation twinning and the stress-strain response of polycrystalline high Mn TWIP steel. Experimental data were compared to predicted results obtained by two polycrystalline models. These two models are based on the same single crystal constitutive equations but differ from the homogenization scheme. The good agreement between experiments and calculations suggest that the texture plays a key role in twinning activity and kinetics with regard to the intergranular stress heterogeneities. Rolling direction simple shear induces single twinning while rolling and transverse direction uniaxial tensions induce multi-twinning leading to lower twin volume fractions due to twin-twin interactions.
\end{abstract}

\section{Introduction}

The high manganese austenitic steels with low stacking fault energy (SFE) present outstanding mechanical properties, with a good compromise between mechanical resistance and ductility [1-3]. The deformation of Fe-Mn-C TWIP steels involves two main strain mechanisms: dislocation glide and twinning. The volume fraction of twins increases with the strain, reducing continually the mean free path of the dislocations. This is called the TWIP effect (Twinning Induced Plasticity), which can be interpreted as a dynamical Hall-Petch effect [4,5]. In order to optimize the mechanical properties of Fe-Mn-C TWIP steels, grain refinement was achieved up. Literature results revealed that decreasing grain size results in increasing the twin stress and so can lead to an inhibition of twinning [6,7]. However, the effect also strongly depends on the chemical composition of the steel. Ueji et al. [7] did not observe anymore twin for an average grain size of $1.8 \mu \mathrm{m}$ for Fe-31 wt\%Mn-3.0 wt\%Al-3.0 wt\%Si TWIP steel whereas Barbier et al. [8] and Gutierrez-Urrutia et al. [6] observed twinning for an average grain size of $\sim 2.6 \mu \mathrm{m}$ to $3 \mu \mathrm{m}$ and $\mathrm{Fe}-22 \mathrm{wt} \% \mathrm{Mn}-0.6 \mathrm{wt} \% \mathrm{C}$ TWIP steel. Concerning the role of grain orientation in $\mathrm{Fe}-\mathrm{Mn}-\mathrm{C}$ TWIP steel, literature results [1,6,9-11] demonstrated that grain orientation played the most dominant role to promote twinning

\footnotetext{
* Corresponding author. Tel.: +330387704253.

E-mail address: david.barbier@arcelormittal.com (D. Barbier).
}

at low-strain levels. For tensile loading, they found that the grains rotate toward the $\langle 111\rangle / /$ tensile axis which favored twinning. This analysis is based on the fact that deformation twinning is observed in grains which fully comply with Schmid's law under the assumption that slip and twinning have equal critical resolved shear stress. It also neglected the presence of stress heterogeneities within the material. Yet, a deviation from Schmid's law is also observed at larger strains mainly attributed to the presence of such stress heterogeneities at the grain scale. In general, stress heterogeneities can be classified into (1) intergranular heterogeneities due to the misorientation between neighbored grains boundaries and (2) intragranular heterogeneities due to the occurrence of twinning and dislocation structures.

To assess the mechanisms responsible for strain hardening behavior, physically based-constitutive equations are very useful. Among them, we can distinguish polycrystalline models which account for the polycrystalline nature (they account for the role of individual grain orientation and use mean or full field homogenization approaches to get the overall behavior [4,12-15]) from models using the average Taylor factor [16-19]. The latter are very useful for material design but not sufficient to predict the behavior and the microstructure changes for various loading paths. Both types of model introduced physically base constitutive equations relating the shear stress to the shear strain or strain rate. However, the polycrystalline models distinguish the various grain orientation slip/twin systems and their anisotropic interactions. The polycrystal response results from the response of individual grains and their 
mechanical interactions. As a consequence, they are suitable to predict intergranular stress/strain heterogeneities, texture evolution and flow curves for various loading paths.

The aim of the paper is to assess interpretation suggested from experimental results obtained for $\mathrm{Fe}-22 \mathrm{wt} \% \mathrm{Mn}-0.6 \mathrm{wt} \% \mathrm{C}$ steel sheet under tensile loading in the Transverse Direction (TD) $[8,9]$ and in Rolling Direction (RD). We focussed on the role of the texture on twinning activity. We also investigated the role of intergranular stresses using two homogenization schemes: the Taylor approximation [20] and an approximation based on the self-consistent method called the translated field model [21]. After tensile loading, we extended comparisons between experiments and calculations to RD shear loading to investigate the impact of the loading path on the strain hardening behavior of such material.

\section{Experimental procedures}

\subsection{Material}

The studied material is an austenitic Fe-Mn-C steel (face centered cubic structure), with a high manganese content. The composition was determined to have a rather low value of the Stacking Fault Energy (SFE) to promote mechanical twinning and TWIP effect ( $S F E \approx 20 \mathrm{~mJ} \mathrm{~m}^{-2}$ ) [3,22]. The optimal chemical composition for the best compromise between ductility and strength at room temperature is $\mathrm{Fe}-22 \mathrm{wt} \% \mathrm{Mn}-0.6 \mathrm{wt} \% \mathrm{C}$ [3]. This TWIP steel, developed by ArcelorMittal Research SA was provided for this study as a $1.3 \mathrm{~mm}$ thick sheet.

The thermo-mechanical processes (hot and cold rolling) and the annealing treatments result in an equiaxed microstructure, with an average grain size of $2.6 \mu \mathrm{m}$.

\subsection{Mechanical testing}

Various mechanical tests were performed at two temperatures. First, a tensile test was conducted at $673 \mathrm{~K}$. The Tensile Axis (TA) was chosen parallel to the sheet Rolling Direction (RD). At this temperature, the SFE is about $80 \mathrm{~mJ} \mathrm{~m}^{-2}$ [22], which is sufficiently high to inhibit mechanical twinning. Hence, the material is then only deformed by crystallographic slip. The parameters of the model related to dislocation glide can thus be identified.
Tensile tests were performed at room temperature according to RD and Transverse Direction (TD) $[1,8]$. In this study, we moreover investigated simple shear. Simple shear tests were conducted on a biaxial testing machine using double shear specimen geometry at Liège University [23]. The shear direction was parallel to the RD. All mechanical testing were conducted at low strain rate $\left(\dot{\varepsilon}=10^{-4} \mathrm{~s}^{-1}\right)$ up to the fracture of the specimen. The equivalent stress and strain for the shear test are calculated with a Hill48 yield criterion [24] in order to account for the initial texture. Interrupted tests at equivalent strains of $\varepsilon_{\text {eq }}=0.1,0.2$ and 0.3 were conducted to investigate the specimen texture and microstructure. The experimental stress-strain curves are presented in Fig. 1.

\subsection{Texture analyses}

The global deformation textures were measured by X-ray diffraction with $\mathrm{Cr} \mathrm{K} \alpha$ radiation. Because of the small width of the gage area of the sheared samples, a special measurement procedure was developed [25]. The experimental poles figures $\{200\}$, $\{220\}$ and $\{111\}$ allow the calculation of the Orientation Distribution Function (ODF) [26]. To represent the texture evolution, the recalculated $\{100\},\{110\}$ and $\{111\}$ poles figures and the $\varphi_{2}=0^{\circ} / \varphi_{2}=45^{\circ}$ ODF sections are used.

To characterize the texture sharpness and its evolution during the deformation, the Texture Index (TI) is used, which is calculated by, $\mathrm{TI}=\oint f(g)^{2} d g$, where $f(g)$ is the ODF.

To compare the experimental and simulated textures, the correlation function $T(\mathrm{~g})$ is defined as follow:

$$
\begin{aligned}
T(g) & =\frac{\int f(g)_{\exp } d g \int f(g)_{\text {sim }} d g}{\sqrt{\oint f(g)_{\exp }^{2} d g} \cdot \sqrt{\oint f(g)_{\text {sim }}^{2} d g}} \\
& =\frac{\int f(g)_{\exp } d g \int f(g)_{\operatorname{sim}} d g}{\sqrt{T I_{\exp }} \cdot \sqrt{T I_{\text {sim }}}}
\end{aligned}
$$

with $f(g)_{\exp }$ the ODF determined from the experimental texture and $f(g)_{\text {sim }}$ from the simulated one. If $T(g)=1$, both texture (experimental and simulated) are identical. The more the two textures diverge, smaller will be the value of the correlation function.

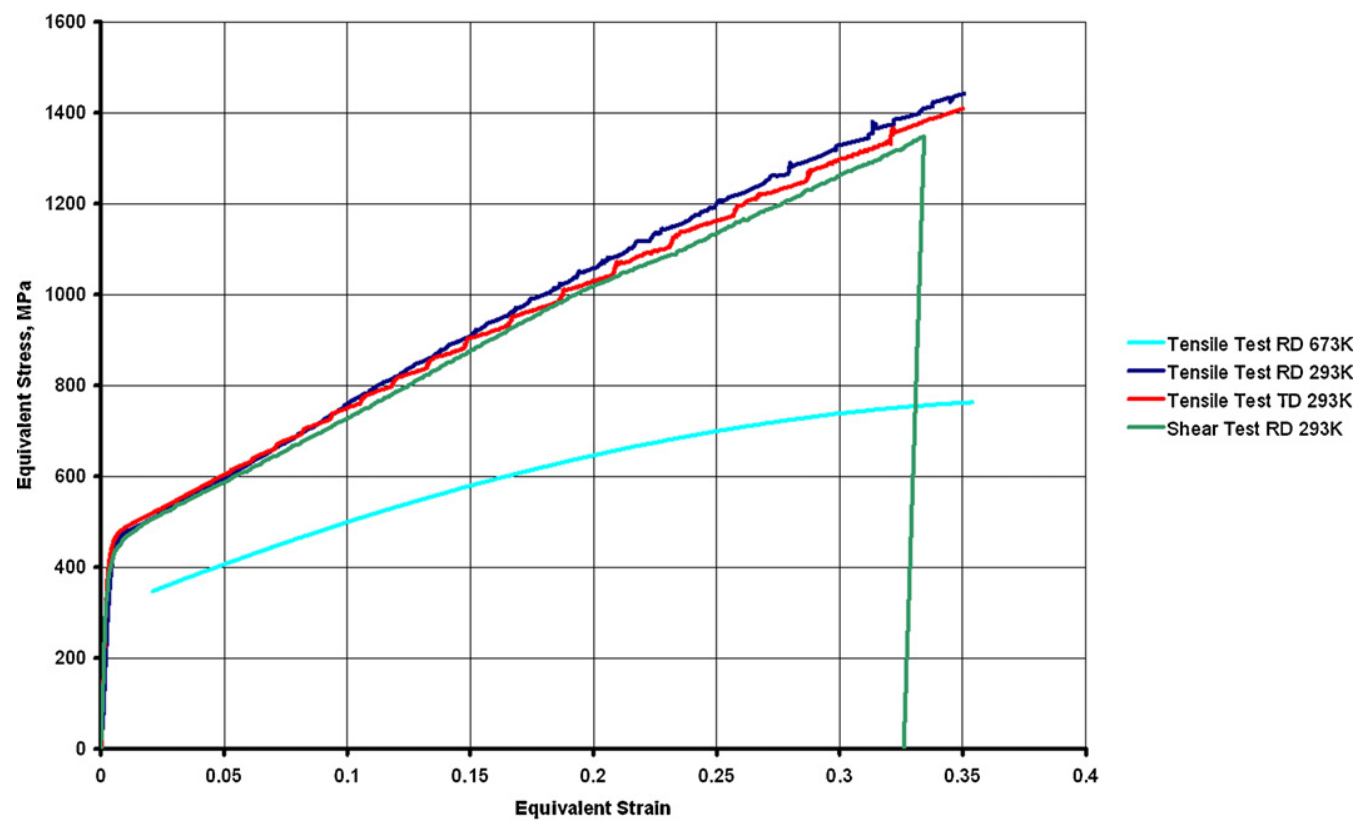

Fig. 1. Experimental stress-strain curves for the tensile tests at $293 \mathrm{~K}$ and $673 \mathrm{~K}$ along the RD and TD, and the shear test at $293 \mathrm{~K}$ along RD. 


\subsection{Microstructure analyses}

To obtain more information about the deformation mechanisms and the TWIP effect during tensile and shear tests, microstructures were investigated at two different scales: microscopic with a Transmission Electron Microscope (TEM) and mesoscopic using a Field Emission Gun Scanning Electron Microscope (FEG SEM) equipped with Electron Back Scattered Diffraction (EBSD) system. TEM analyses were performed on samples strained in tension (TA//TD) at different levels. All microstructural observations were performed in the RD-TD plane.

\section{Elasto-viscoplastic polycrystalline model}

We consider a Representative Volume Element (RVE) including 3000 grain orientations to estimate the overall behavior of the high Mn TWIP steel polycrystal of interest. We used an elastic-viscoplastic single crystal constitutive equation based on crystal plasticity issued from [15]. The overall behavior is deduced from two homogenization schemes: Taylor's approximation [20] and the translated field model developed by Sabar et al. [21].

\subsection{Single crystal constitutive equation}

Adopting the small strain hypothesis, the local strain rate $\dot{\varepsilon}$ is decomposed into an elastic part $\dot{\varepsilon}^{e}$ and a viscoplastic part $\dot{\varepsilon}^{v p}$ (Maxwell's model). Here, we consider the average variables over a grain orientation.

$\dot{\varepsilon}_{i j}=\dot{\varepsilon}_{i j}^{e}+\dot{\varepsilon}_{i j}^{v p}$

The elastic anisotropy is neglected with regard to the plastic anisotropy so that the tensor of elastic moduli $C$ depends only on the elastic shear modulus $\mu$ and Poisson's ratio $v$. Hooke's law is written:

$\dot{\sigma}_{i j}=C_{i j k l}(\mu, v): \dot{\varepsilon}_{i j}^{e}$

where $\dot{\sigma}$ is the average stress rate tensor over a grain orientation.

As described fully in [15], the viscoplastic deformation accounts for the two inelastic strain mechanisms involved in the deformation of TWIP steel, i.e. crystallographic slip and mechanical twinning. Thus, the viscoplastic strain rate is written (3):

$\dot{\varepsilon}_{i j}^{v p}=\left(1-\sum_{h}^{N^{(h)}} f^{(h)}\right) \sum_{g}^{N^{(g)}} R_{i j}^{(g)} \dot{\gamma}^{(g)}+\sum_{h}^{N^{(h)}} R_{i j}^{t w(h)} \dot{f}^{(h)} \gamma^{t w}$

with

$R_{i j}^{(g)}=\frac{1}{2}\left(t_{i}^{(g)} n_{j}^{(g)}+t_{j}^{(g)} n_{i}^{(g)}\right)$

and

$R_{i j}^{t w(h)}=\frac{1}{2}\left(t_{i}^{t w(h)} n_{j}^{t w(h)}+t_{j}^{t w(h)} n_{i}^{t w(h)}\right)$

The indexes $(g)$ and $(h)$ are related to the slip and twin systems, respectively. $t w(h)$ refers to twinning mechanisms on the system $h$.

$R_{i j}^{(g)}$ and $R_{i j}^{t w(h)}$ are the Schmid tensors associated with the slip/twin systems, respectively, with normal $n^{(g), t w(h)}$ and slip/twin directions $t^{(g), t w(h)}$. They are calculated, respectively, for 12 potentially $\left\{\begin{array}{lll}1 & 1 & 1\end{array}\right\}\langle 110\rangle$ slip systems and $\left\{\begin{array}{llll}1 & 1 & 1\end{array}\right\}\left\langle\begin{array}{lll}1 & 1 & 2\end{array}\right.$ twinning systems (which supposes that twins nucleate thanks to intrinsic stacking faults). $\dot{\gamma}^{(g)}$ is the slip rate of the system $(g), f^{(h)}$ denotes the volume fraction of the twinned regions associated with the system $(h), N^{(g)}$ and $N^{(h)}$ represent the number of potentially active slip and twin systems, respectively. The mechanical twinning rate $\dot{\gamma}^{t w(h)}=\dot{f}^{(h)} \gamma^{t w}$ depends on the twin volume fraction rate and the characteristic twin shear $\gamma^{t w}=1 / \sqrt{2}$.

This approach has been followed by many authors to describe twinning $[14,27,28]$. The crystallographic slip rate $\dot{\gamma}^{(g)}$ is described using a multi-slip systems approach according to [29]:

$\dot{\gamma}^{(g)}=\dot{\gamma}_{0}\left(\frac{\tau^{(g)}}{\mu}\right)^{2} \exp \left(-\frac{\Delta G_{0}}{k T}\left(1-\left(\frac{\left|\tau^{(g)}\right|}{\tau_{r}^{(g)}}\right)\right)\right) \operatorname{sign}\left(\tau^{(g)}\right)$

where $\tau^{(g)}$ is the resolved shear stress associated with the slip ( $g$ ) and is calculated by

$\tau^{(g)}=R_{i j}^{(g)} \sigma_{i j}$

$\dot{\gamma}_{0}$ is a reference slip rate, $\mu$ is the elastic shear modulus, $T$ is the absolute temperature, $k$ is the Boltzman constant, $\Delta G_{0}$ is the activation energy required to overcome an obstacle without any help of stresses (when $\tau^{(g)}=0$ ). The reference shear stress $\tau_{r}^{(g)}$, for a slip system $(g)$, evolves with the densities of the forest dislocations $\rho^{(h)}$ and is expressed by the following expression [30]:

$\tau_{r}^{(g)}=\tau_{r 0}^{(g)}+\alpha \mu b \sqrt{\sum_{h} a^{(g h)} \rho^{(h)}}$

$\tau_{r 0}^{(g)}$ is the initial reference shear stress of the gth system (identical on all the slip systems and all the grains), $\alpha$ is a material constant representing the resistance of the forest dislocations, $b$ is the magnitude of the Burgers vector and $a^{(g h)}$ is the symmetric $(12 \times 12)$ slip-slip interaction matrix inspired of the Francoisi's work [30].

The dislocation density evolution law from Kocks and Mecking [31] takes into account the storage and the dynamic recovery of dislocations and is expressed as:

$\dot{\rho}^{(g)}=\frac{1}{b}\left(\frac{1}{L^{(g)}}-\beta \rho^{(g)}\right)\left|\dot{\gamma}^{(g)}\right|$

$\beta$ is a parameter which describes the dynamic recovery. $L^{(g)}$ is the dislocation Mean Free Path (MFP) of the system $(g)$ calculated by Eq. (14).

The evolution of the twin volume fraction, which is considered as an internal variable, is given by:

$\dot{f}^{(h)}=\dot{f}_{0}\left(1-\sum_{t=1}^{12} f^{(t)}\right)\left(\frac{\tau^{t w(h)}}{\tau_{c}^{t w(h)}}\right)$ when $\tau^{t w(h)}>\tau_{c}^{t w(h)}$

where $\tau^{t w(h)}$ is the resolved shear stress associated with the twinning system $(h)$ and is calculated by:

$\tau^{t w(h)}=R_{i j}^{t w(h)} \sigma_{i j}$

$\dot{f}_{0}$ is the reference twinning rate. The critical shear stress for twinning $\tau_{c}^{t w(h)}$ is obtained from experimental data. If this critical shear stress is not reached, i.e. $\tau^{t w(h)} \leq \tau_{c}^{t w(h)}$, no twins are activated, and then $\dot{f}^{(h)}=0$. This power type evolution law for the twin volume fraction rate is inspired from Kalidindi work's [28]. In this approach, and conversely of Proust work's on hexagonal materials [32], no de-twinning is allowed (i.e. $\dot{f}^{(h)} \geq 0$ ), which is consistent with our experimental observations.

The evolution of the twinning shear stress is describe using a law proposed by Kalidindi [13], which takes into account the twin-twin 
interactions and distinguishes the coplanar and non-coplanar twin systems.

$$
\begin{aligned}
\dot{\tau}_{c}^{t w(t)}= & h_{n c p}^{t w}\left(\sum_{t=1}^{12} f^{(t)}\right)^{\alpha} \underbrace{\sum \gamma^{t w} \dot{f}^{(k)}}_{k \in \text { non-coplanar twin system with } t} \\
& +h_{c p}^{t w}\left(\sum_{t=1}^{12} f^{(t)}\right) \underbrace{\sum \gamma^{t w} \dot{f}^{(k)}}_{k \in \text { coplanar twin system with } t}
\end{aligned}
$$

$\alpha, h_{n c p}^{t w}$ and $h_{c p}^{t w}$ are parameters that have to be adjusted to describe the twinning kinetics.

The effect of twinning on the hardening is taken into account in the expression of the Mean Free Path (MFP) of the dislocations. $L^{(g)}$ represents the MFP of the dislocations of the $(g)$ system and takes into account the obstacles to the dislocation motion. In materials which are only deformed by slip, the mean free path depends on the grain boundaries and on the dislocation-dislocation interactions. In the case of TWIP steels, twins act as strong obstacles to the dislocation motion. The expression of the MFP is then:

$$
\frac{1}{L^{(g)}}=\frac{1}{D}+\frac{\sqrt{\sum_{i \neq g} \rho^{i}}}{K}+B^{g h} \frac{f^{(h)}}{2 \operatorname{re}\left(1-\sum_{k=1}^{12} f^{(k)}\right)}
$$

$D$ is the effective grain size, $K$ is a constant. The last term of Eq. (14) represents the spacing between the twins secant to the slip system (g) according to Allain et al.'s work [27]. It depends on the twin volume fraction $f$, the mean twin thickness $e$ and the mean number of twins per stack $r$. These two parameters, $e$ and $r$, are chosen to be constant during the deformation for all twin systems. This point will be highlighted in the next section. However, Soulami et al. [18] showed that the thickness of the deformation twins depend strongly on the grain size and grain orientation $(10-70 \mathrm{~nm}$ for similar conditions as ours).

$B^{g h}$ represents the slip-twin (respectively, $g$ and $h$ index) interaction matrix defined as followed:

$B^{g h}=0$ if $(g)$ slip system and $(h)$ twin system are coplanar. $B^{g h}=1$ if $(g)$ slip system and $(h)$ twin system are secant.

Finally, combining Eqs. (4), (7), (8), (11) and (12), the local viscoplastic strain rate can be written:

$\dot{\varepsilon}_{i j}^{v p}=m_{i j k l} \sigma_{k l}$

where the tensor of viscoplastic compliances $m$ is written

$$
\begin{aligned}
m_{i j k l}= & \sum_{g}^{N^{(g)}}\left(1-\sum_{h}^{N^{(h)}} f^{(h)}\right) \dot{\gamma}_{0} \frac{\left|\tau^{(g)}\right|}{\mu} \\
& \times \exp \left(-\frac{\Delta G_{0}}{k T}\left(1-\left(\frac{\left|\tau^{(g)}\right|}{\tau_{r}^{(g)}}\right)\right)\right) \operatorname{sign}\left(\tau^{(g)}\right) R_{i j}^{(g)} R_{k l}^{(g)} \\
& +\sum_{h}^{N^{(h)}} \gamma^{t w} \frac{\dot{f}_{0}}{\tau_{c}^{t w(h)}}\left(1-\sum_{t=1}^{12} f^{(t)}\right) R_{i j}^{t w(h)} R_{k l}^{t w(h)}
\end{aligned}
$$

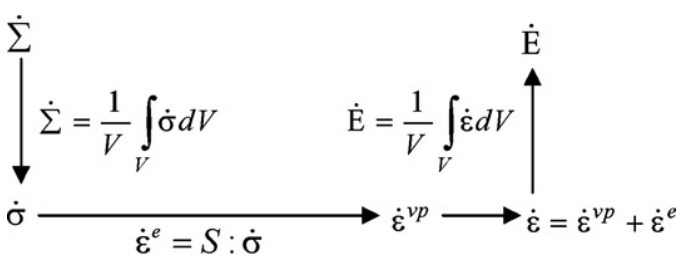

Fig. 2. Schematic representation of the homogenization scheme.

The grain rotations due to slip are given by the evolution of the Euler angles as defined by Bunge and Fuchs [33].

$$
\begin{aligned}
& \dot{\varphi}_{1}=\frac{\sin \varphi_{2}}{\sin \phi} \cdot \dot{\omega}_{13}^{r}-\frac{\cos \varphi_{2}}{\sin \phi} \cdot \dot{\omega}_{21}^{r} \\
& \dot{\varphi}_{2}=\cos \phi \cdot\left(\frac{\cos \varphi_{1}}{\sin \phi} \cdot \dot{\omega}_{13}^{r}+\frac{\sin \varphi_{1}}{\sin \phi} \cdot \dot{\omega}_{23}^{r}\right)+\dot{\omega}_{21}^{r} \\
& \dot{\phi}=-\cos \varphi_{2} \cdot \dot{\omega}_{23}^{r}+\sin \varphi_{2} \cdot \dot{\omega}_{13}^{r}
\end{aligned}
$$

where $\varphi_{1}, \phi, \varphi_{1}$ are the Euler angles. In small strain hypothesis, the lattice rotation of each grain is given by:

$\dot{\omega}_{i j}^{r}=\dot{\omega}_{i j}-\dot{\omega}_{i j}^{v p}$

where $\dot{\omega}$ is the total spin tensor due to interactions between each grain with its surroundings. For spherical grains and when assuming isotropic modulus, it can be shown that [34]:

$\dot{\omega}_{i j}=\dot{\Omega}_{i j}$

where $\dot{\Omega}$ is the macroscopic spin tensor.

Here, we assumed that $\dot{\Omega}=0$ and that the lattice rotation $\dot{\omega}_{i j}^{r}$ of each grain results from the crystallographic slip in the untwined region. In other words, we neglected texture associated with twinning since the twin volume fraction remains low $(<10 \%)$ during the deformation. It leads:

$\dot{\omega}_{i j}^{r}=-\left(1-\sum_{n}^{N^{t w}} f^{(h)}\right) \sum_{g} R_{i j}^{\perp(g)} \dot{\gamma}^{(g)}$

where

$R_{i j}^{\perp(g)}=\frac{1}{2}\left(t_{i}^{(g)} n_{j}^{(g)}-t_{j}^{(g)} n_{i}^{(g)}\right)$

\subsection{Homogenization scheme}

Accounting properly for the interaction of the grains with their surroundings is of the most importance in any polycrystal model. The strength of such interaction dictates how much overall deformation will be accommodated the grain and its surroundings. The classical Taylor model assuming the hypothesis of equal strain or here strain rate in every grain fulfils the compatibility conditions and is known to give a good description of texture development in anisotropic materials such as low SFE fcc metals [12,35] and hcp metals [36]. However, it results to an extremely rigid interaction because it describes pure elastic interactions. Sabar et al. [21] developed an interaction law which successfully represents the elastic-viscoplastic interactions between grains. This model, labelled as the translated field model, is inspired from the selfconsistent approximation. In this work, both interactions law are used in order to estimate their relevance for the Fe-Mn-C steel response in stress-strain curves, twinning kinetics and texture development for different loading paths. The scheme adopted to obtain the global behavior of the polycrystal is given in Fig. 2 .

The interaction law for the Taylor assumption [20] is written:

$\dot{E}=\dot{\varepsilon}$

where $\dot{E}$ the macroscopic strain rate tensor. 


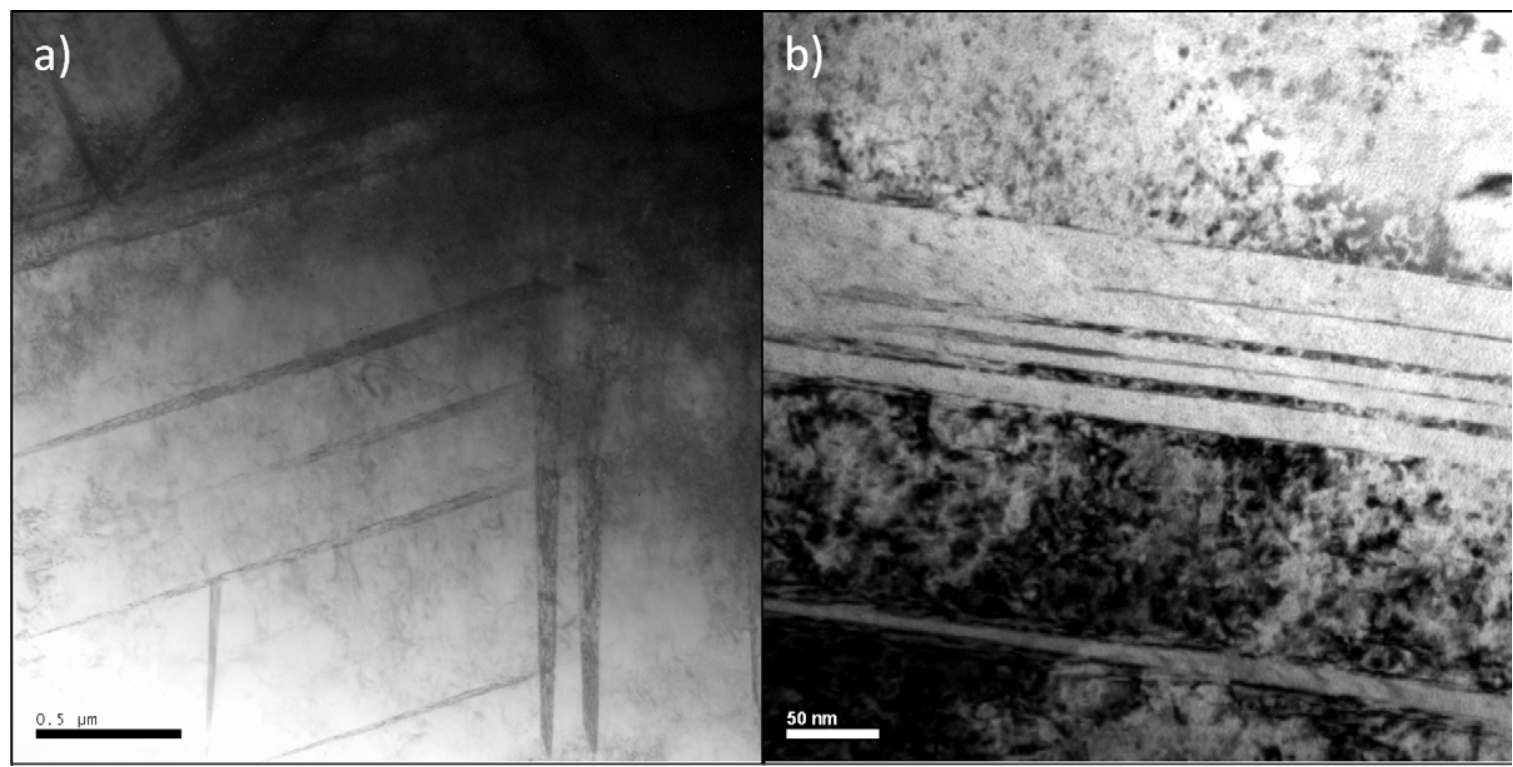

Fig. 3. TEM analyses on samples deformed in tension (a) at $\varepsilon_{t}=0.05$ and (b) at $\varepsilon_{t}=0.3$.

The interaction law for the translated field model inspired from self-consistent approximation Sabar et al. [21] is written:

$\dot{\sigma}=\dot{\Sigma}-C:\left(I-S^{E}\right):\left(\dot{\varepsilon}^{v p}-A^{B^{e}}: \dot{E}^{v p e}\right)$

$\dot{\Sigma}$ is the macroscopic stress rate. $I$ is the identity tensor and $S^{E}$ is the elastic Eshelby tensor. $A^{B^{e}}$ the localization tensor of the viscoplastic strain rate calculated by the self-consistent approximation associated with a pure viscoplastic heterogeneous problem. $\dot{E}^{v p e}$ the overall viscoplastic strain rate equal to the average of the local viscoplastic strain rate over the RVE for elastic homogeneous materials, i.e. $\dot{E}^{v p e}=\overline{\dot{\varepsilon}^{v p}}$. The present scale transition model is based on the introduction of a viscoplastic strain rate translated field so that the real viscoplastic strain rate field is written as the sum of a reference strain rate field (the translated field) and some fluctuations .The translated field is chosen as the solution of the purely viscoplastic heterogeneous problem $A^{B^{e}}: \dot{E}^{v p e}$. As a result, the translated field and the fluctuations change along the deformation as the applied loading but also the grain responses change (non linear behavior). This provides an accurate estimation of the interactions deformation between grains when the self-consistent approximation is performed". Further details are found in Sabar et al. [21] The model was implemented using an incremental explicit scheme. The stress-strain response and the microstructure evolution of the polycrystal were predicted by applying constant strain rate tensor to the polycrystal. At each time increment, the tensor of viscoplastic moduli the localization tensor of the viscoplastic strain rate are calculated assuming a pure viscoplastic heterogeneous problem. Then, the rate of the local variables including the stress and strain rates are deduced from the interaction law and single crystal constitutive equations. Using an averaging procedure, the macroscopic stress rate is determined. Finally, the local variables including the local stress and strain and the macroscopic variables are updated after each time increment.

\section{Results and discussion}

\subsection{Experimental results}

The results concerning the microstructural evolutions in tension are recalled. More detailed can be found in $[8,9]$. Fig. 3 shows dark field images on samples strained at $\varepsilon_{t}=0.05$ and 0.3 . These analyses show that: (i) Twins are activated in the earlier stage of deformation, i.e. at $\varepsilon_{t}=0.02$.

(ii) At $\varepsilon_{t}=0.05$, some grains exhibit two twinning systems as shown in Fig. 3a. The mean twin thickness is $30 \mathrm{~nm}$.

(iii) With increasing the strain, the thickness remains constant but the number of twins per bundles increases (Fig. 3b).

To obtain more information about the deformation mechanisms of this high Mn TWIP steel, a large number of high resolution
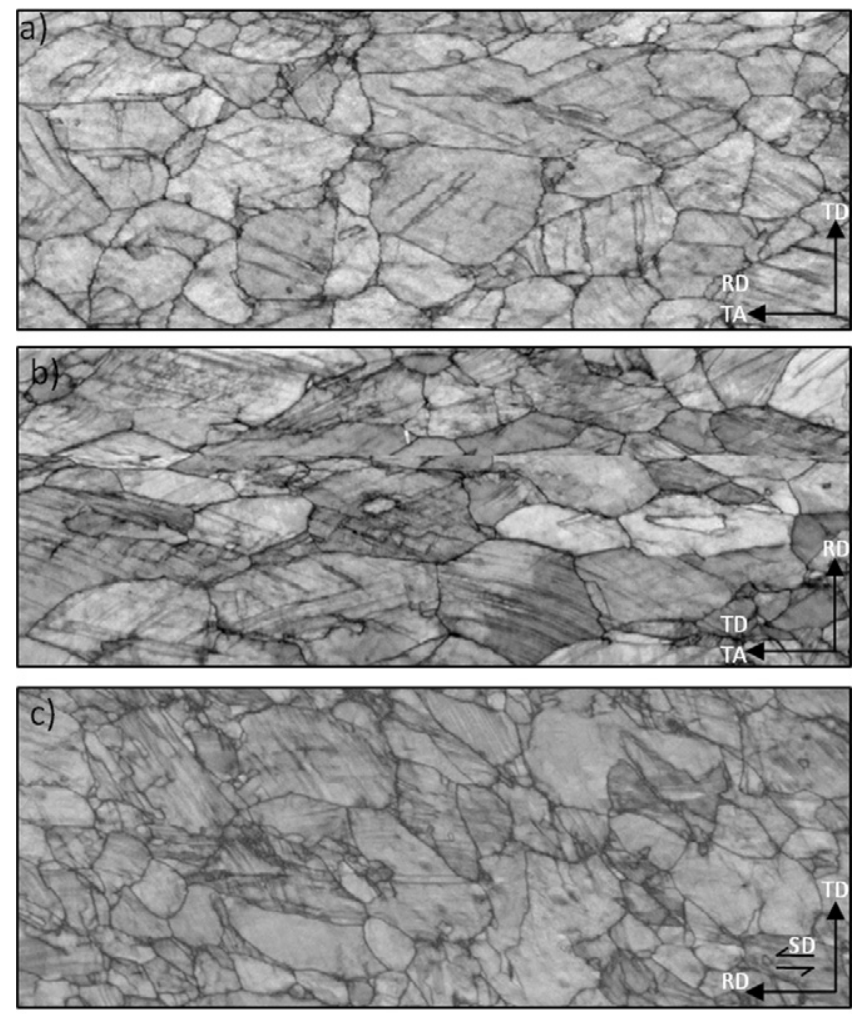

$5 \mu \mathrm{m}$

Fig. 4. Band contrast maps (a) tensile RD; (b) tensile TD; and (c) shear RD 

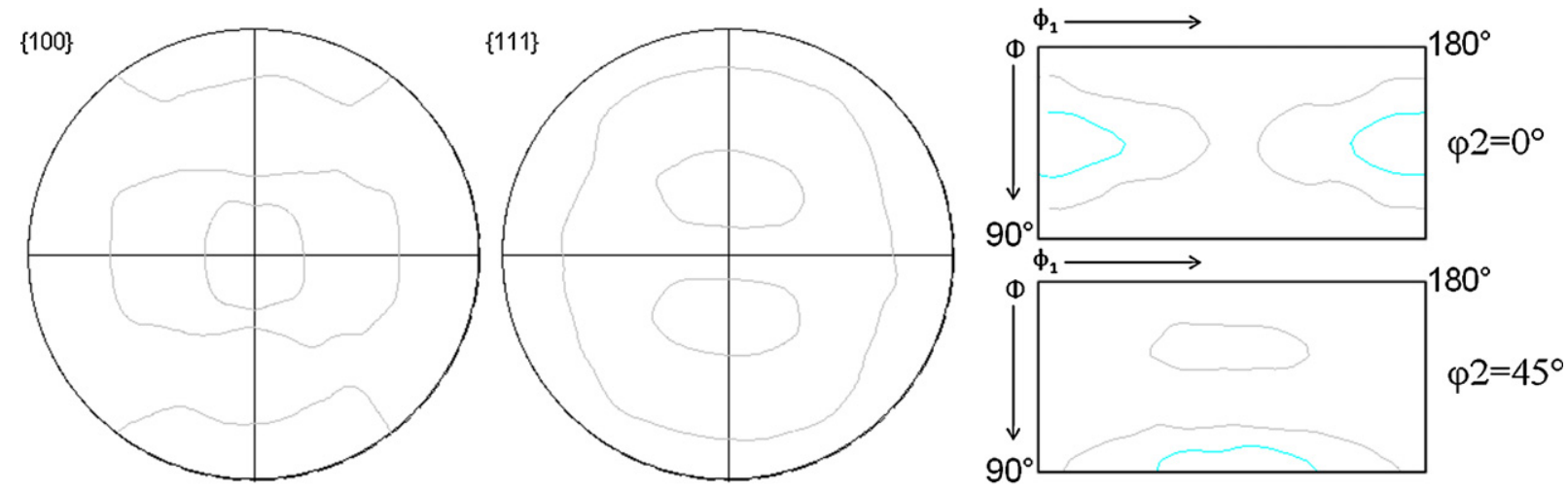

(a)

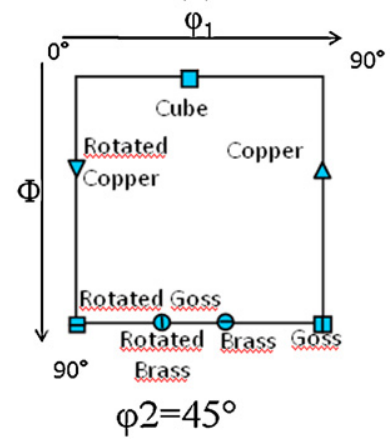

(b)
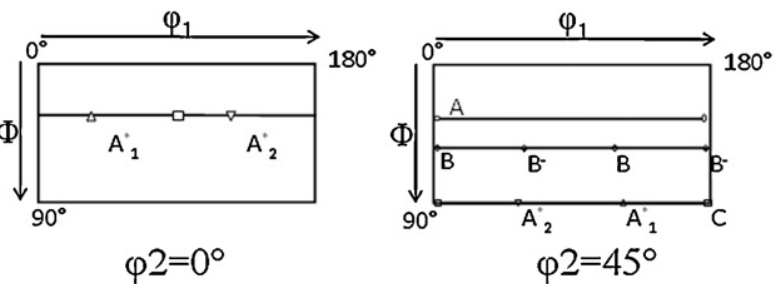

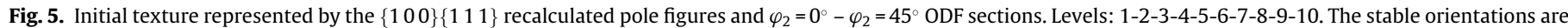
also indicated for the tensile tests (a) and for the shear test (b).
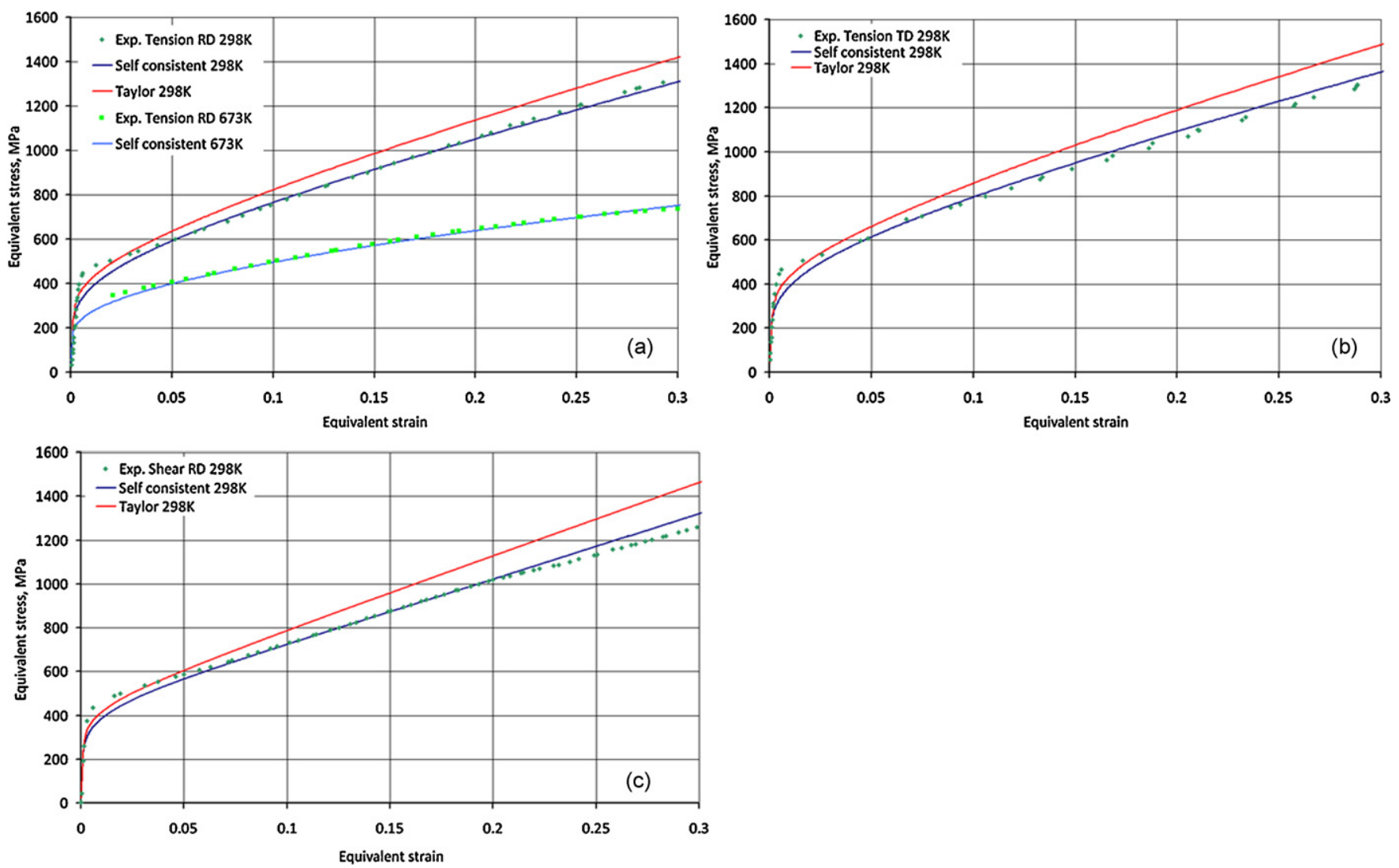

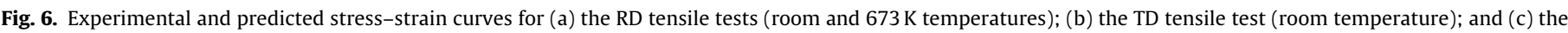
$\mathrm{RD}$ shear test (room temperature). 


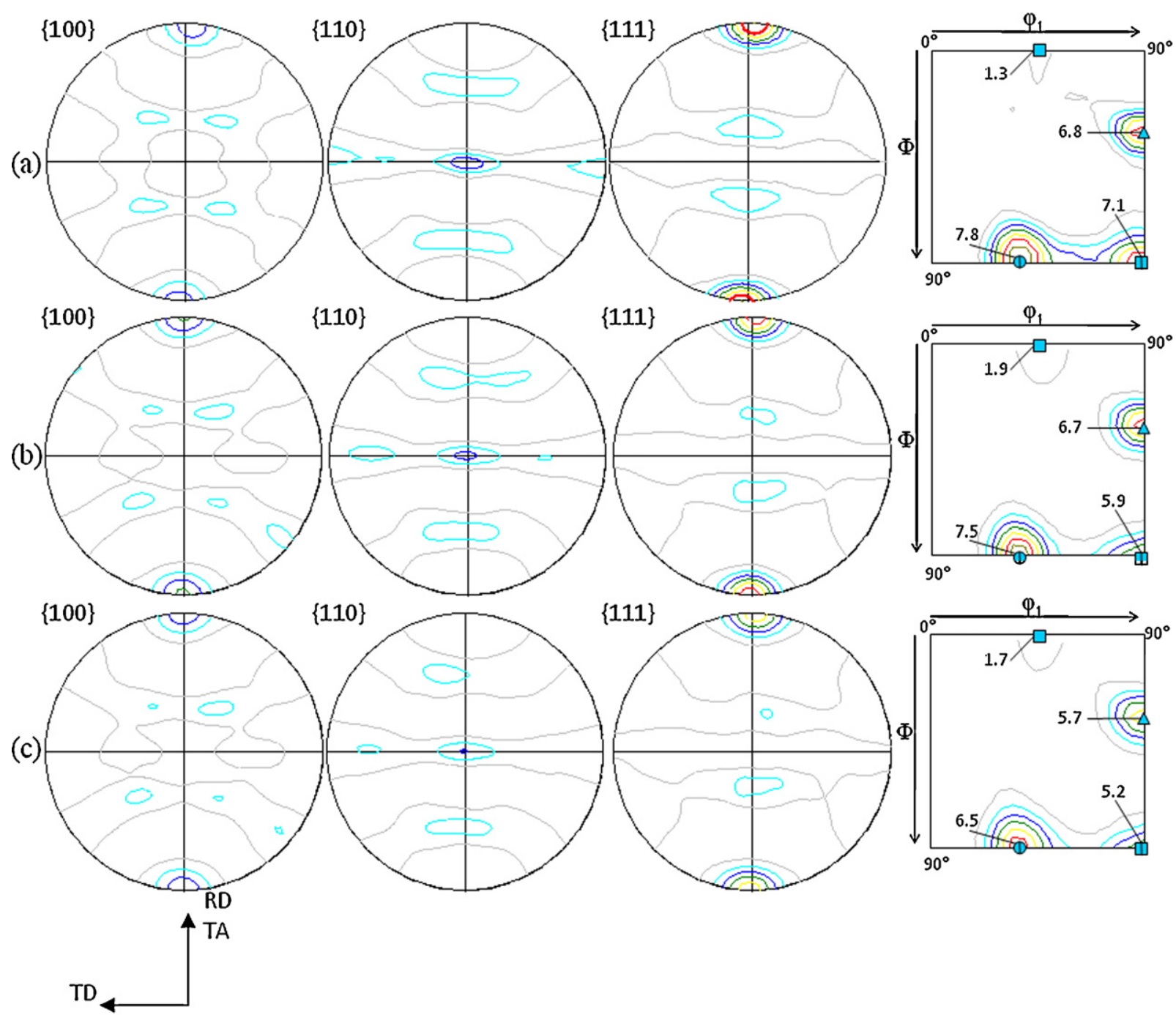

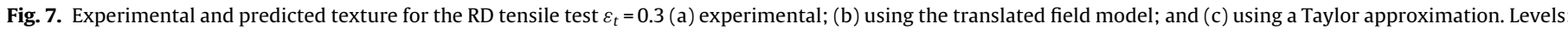
1-2-3-4-5-6-7-8-9-10.

EBSD scans were performed on the samples for each mechanical tests, and thus at different strain levels. Fig. 4 presents the results obtained on samples strained at $\varepsilon_{t}=0.3$ in tension and shear loading. The main features that can be deduced from these EBSD scans are:

(i) In tension, almost all the grains exhibit one or two twinning systems. The proportion of grains having one twinning system is above the one having two twinning systems.

(ii) The volume fraction of twins is higher in the RD case [1].

(iii) In shear testing, most of the grains exhibit one twinning system.

(iv) For the shear testing, around $10 \%$ of the grains are only deformed by crystallographic slip (no twinning system is visible) compared to the few un-twinned grains during tensile testing.

(v) In all cases, the volume fraction of twins remains low, i.e. less than $10 \%[8]$.

\subsection{Parameters identification}

We simulated RD and TD tensions as well as RD simple shear to assess the role of the texture and the intergranular stresses on slip and deformation twinning and stress-strain responses. The parameters of the model which are given in Table 1 can be divided in three groups, material parameters (MP), slip parameters (SP) and twinning parameters (TP). They are either determined from bibliography, by experimental measurements (EM) or by curve-fitting (CF). For the curve-fitting, we used RD tensile tests at $673 \mathrm{~K}$ and $293 \mathrm{~K}$. First, the material parameters (MP) are:

(i) The shear modulus $\mu=65 \mathrm{GPa}$ (determined by Dynamic Mechanical Thermal Analysis [27]).

(ii) The initial dislocation density $\rho_{0}=1 \times 10^{13} \mathrm{~m}^{-2}$ (estimated by X-ray diffraction [37]),

(iii) The mean grain size $D=2.6 \mu \mathrm{m}$ (measured by EBSD).

The second group is the slip parameters (SP). These parameters are obtained using the tensile test at $673 \mathrm{~K}$. In fact, at this temperature, the SFE is sufficiently high to inhibit mechanical twinning. The material is then only deformed by crystallographic slip.

(i) The initial reference shear stress $\tau_{r 0}^{(g)}$ is equal to $135 \mathrm{MPa}$ (measured using the stress-strain curve and assuming that the yield stress is about twice higher than $\left.\tau_{r 0}^{(g)}\right)$.

(ii) The Burgers vector equal to $0.256 \mathrm{~nm}$ [27].

(iii) The dynamical recovery $\beta$, the reference slip rate $\dot{\gamma}_{0}$ and the parameter $K$ link to the forest dislocations are adjusted to match the stress-strain curve at $673 \mathrm{~K}$ 


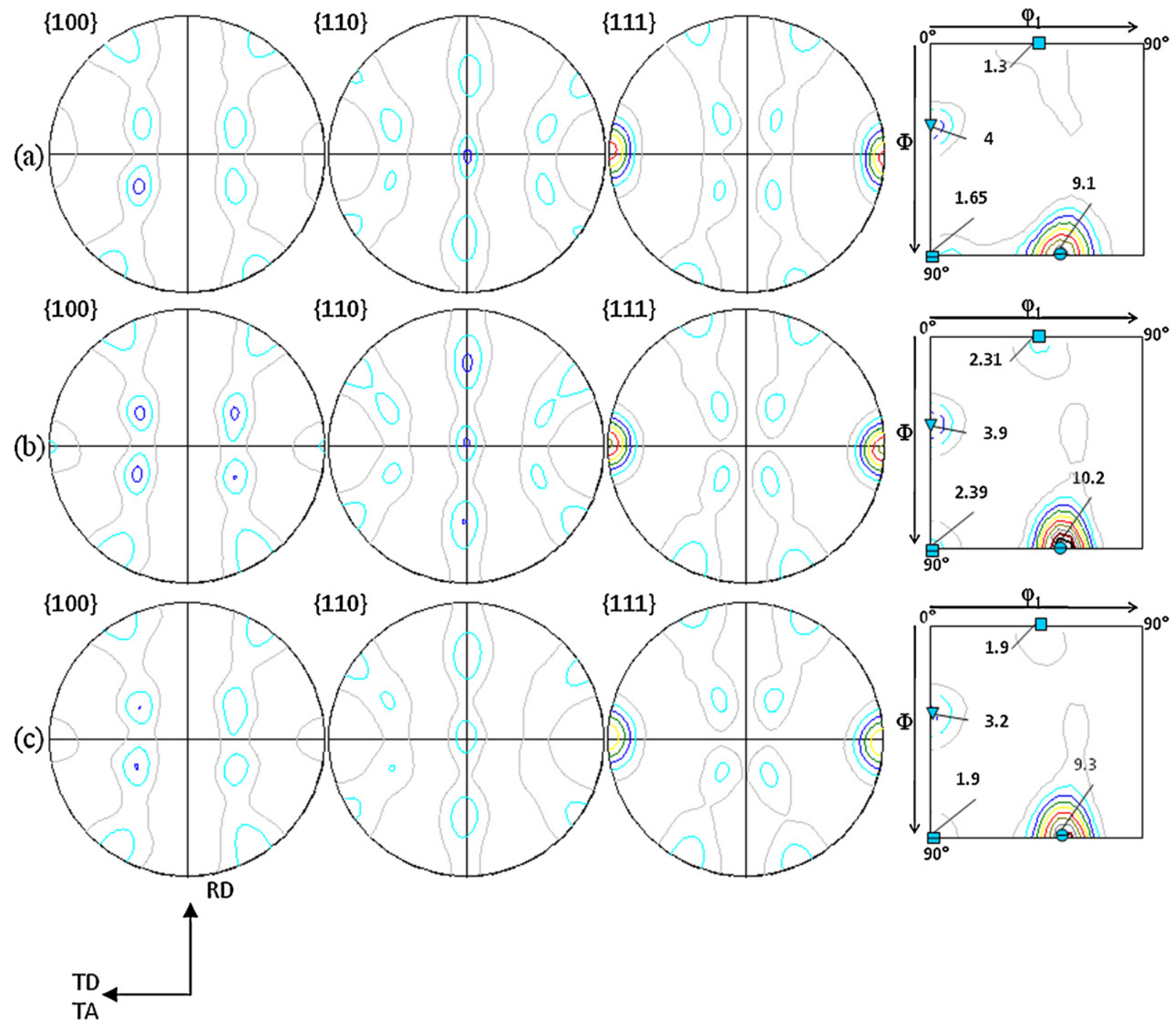

Fig. 8. Experimental and predicted texture for the TD tensile test $\varepsilon_{t}=0.3$ (a) experimental; (b) using the translated field model; and (c) using a Taylor approximation. Levels: $1-2-3-4-5-6-7-8-9-10$.

(iv) The activation energy for slip $\Delta G_{0}$, adjusted to $1 \mathrm{eV}$ (close from the value $\left.0.1 \mu \mathrm{b}^{3}[38,39]\right)$,

The obtained SP are then kept constant for the subsequent simulations at $293 \mathrm{~K}$. Finally, the twinning parameters are determined using the tensile curve at $293 \mathrm{~K}$, where both deformation mechanisms, slip and mechanical twinning, are activated.

(i) The mean twin thickness e and the mean number of twins per bundles are determined with the TEM analyzes.

Table 1

Values of the physical constants and identified parameters.

\begin{tabular}{|c|c|c|c|c|}
\hline & Symbol & Value & Meaning & Determination \\
\hline \multirow{3}{*}{ Material parameters } & $\mu$ & $65 \mathrm{GPa}$ & Shear modulus & [27] \\
\hline & $\rho_{0}$ & $1.10^{13} \mathrm{~m}^{-2}$ & Initial dislocations density & [37] \\
\hline & $D$ & $2.6 \mu \mathrm{m}$ & Mean grain size & EM \\
\hline \multirow{7}{*}{ Slip parameters } & $\tau_{r 0}^{(g)}$ & $135 \mathrm{MPa}$ & Initial reference shear stress & EM \\
\hline & $\beta^{r 0}$ & $9 \times 10^{-9}$ & Dynamic recovery coefficient & $\mathrm{CF}$ \\
\hline & $b$ & $0.256 \mathrm{~m}$ & Burger vector & {$[27]$} \\
\hline & $k$ & 33.5 & Dislocations forest interaction coefficient & $\mathrm{CF}$ \\
\hline & $\dot{\gamma}_{0}$ & $5.77 \times 10^{5} \mathrm{~s}^{-1}$ & Reference slip rate & $\mathrm{CF}$ \\
\hline & $\Delta G_{0}$ & $1 \mathrm{eV}$ & Activation energy & [39] \\
\hline & & & & {$[38]$} \\
\hline \multirow{6}{*}{ Twinning parameters } & $e$ & $30 \mathrm{~nm}$ & Mean twin thickness & EM \\
\hline & $\tau_{c}^{(t w)}$ & $200 \mathrm{MPa}$ & Critical shear stress for twinning & EM \\
\hline & $\dot{f}_{0}$ & $5 \times 10^{-5} s^{-1}$ & Twinning rate reference & $\mathrm{CF}$ \\
\hline & $\alpha$ & 0.01 & Hardening parameters & $\mathrm{CF}$ \\
\hline & $h_{n c p}^{t w}$ & $3.5 \times 10^{3}$ & Twinning kinetics parameter & $\mathrm{CF}$ \\
\hline & $h_{c p}^{t w}$ & $1.5 \times 10^{4}$ & Twinning kinetics parameter & $\mathrm{CF}$ \\
\hline
\end{tabular}


(ii) The critical shear stress for twinning $\tau_{c}^{t w(h)}$ is adjusted from the experimental observations, i.e. to start the twinning activity at $\varepsilon_{\text {eq }}=0.02$. Gutierrez-Urrutia et al. [6] observed that at low strain, a strong influence of grain orientation on deformation twinning is observed which fully complies with Schmid's law under the assumption that slip and twinning have equal critical resolved shear stress. In our case, $\tau_{c}^{t w(h)}$ was taken a bit higher than $\tau_{r 0}^{(g)}$ to start the twinning activity at $\varepsilon_{\text {eq }}=0.02$.

(iii) The parameters linked to the twinning kinetics $\left(\dot{f}_{0}, \alpha, h_{n c p}^{t w}\right.$ and $\left.h_{c p}^{t w}\right)$ are adjusted from the experimental results.

All these parameters are either deduced from experimental measurements or adjusted on tensile tests ( $673 \mathrm{~K}$ and $293 \mathrm{~K}$ ) in the RD. To simulate the tensile test along the TD and the shear test along the $\mathrm{RD}$, the parameters are kept constant, i.e. no new identification is performed. This strategy is used to analyze the predictive capacities of the model.

The initial texture (Fig. 5), measured by X-ray diffraction, has been discretized in a Representative Volume Element (RVE) of 3000 individual orientations.

\subsection{Results and discussion}

The model proposed in Section 3 is now applied to simulate the deformation behavior, the texture evolution and the twinning kinetics of the Fe-Mn-C TWIP steel. Three mechanical testing are simulated: tensile tests along RD and TD and simple shear along RD in the RD-TD plane.Stress-strain responses

The predicted and experimental stress-strain curves are represented in Fig. 6. First, the simulations of the RD tensile test are showed in Fig. 6a. The test at $673 \mathrm{~K}$ is fitted to obtain the slip parameters with the translated field model. Then the simulation is performed at room temperature. The curve is fitted to obtain the twinning parameters. The earlier stages of the deformation, corresponding to the micro-plasticity stage, are not well reproduced. These discrepancies are due to the use of a pure viscoplastic framework to describe plastic mechanisms (see, e.g. [29]). Indeed, no threshold shear stress (critical shear stress) was introduced to control the onset of slip. As a result, all the slip systems are active as soon as the stress is not null (though at very small slip magnitudes), leading to a smooth elastic-plastic transition. After 0.05 true strain, experimental and predicted curves are in good agreement. With (a)
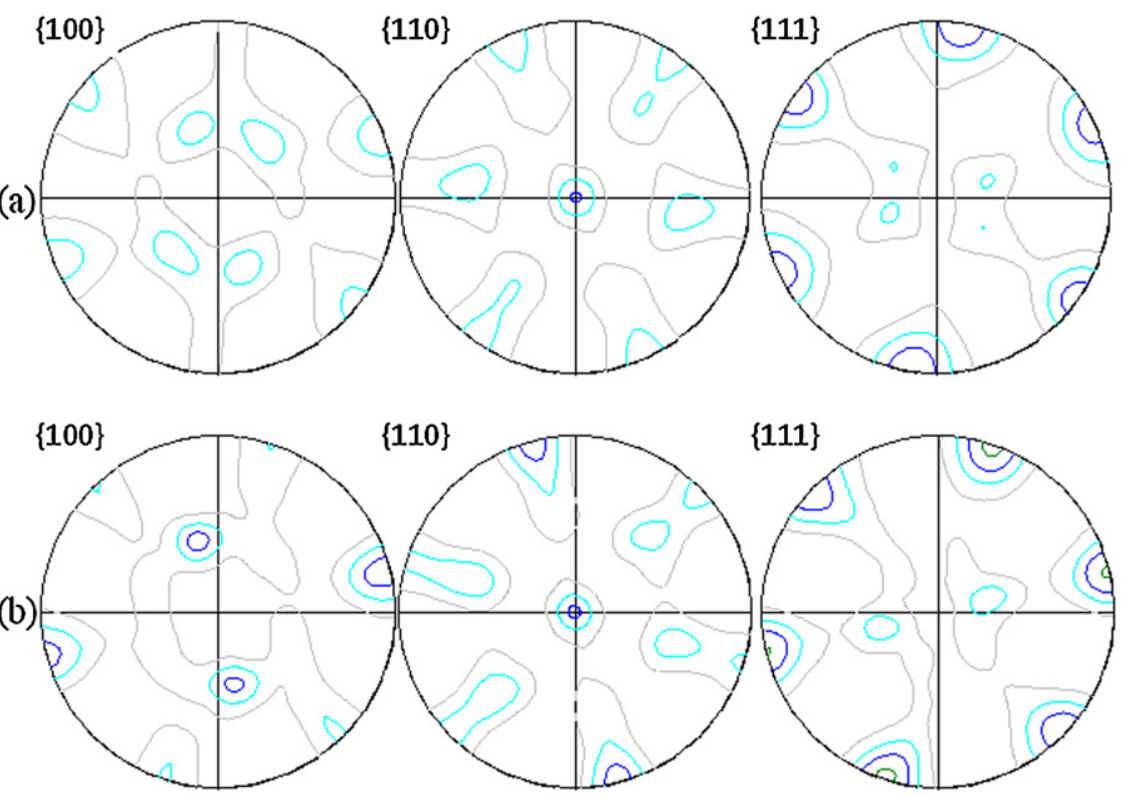

$\{111\}$
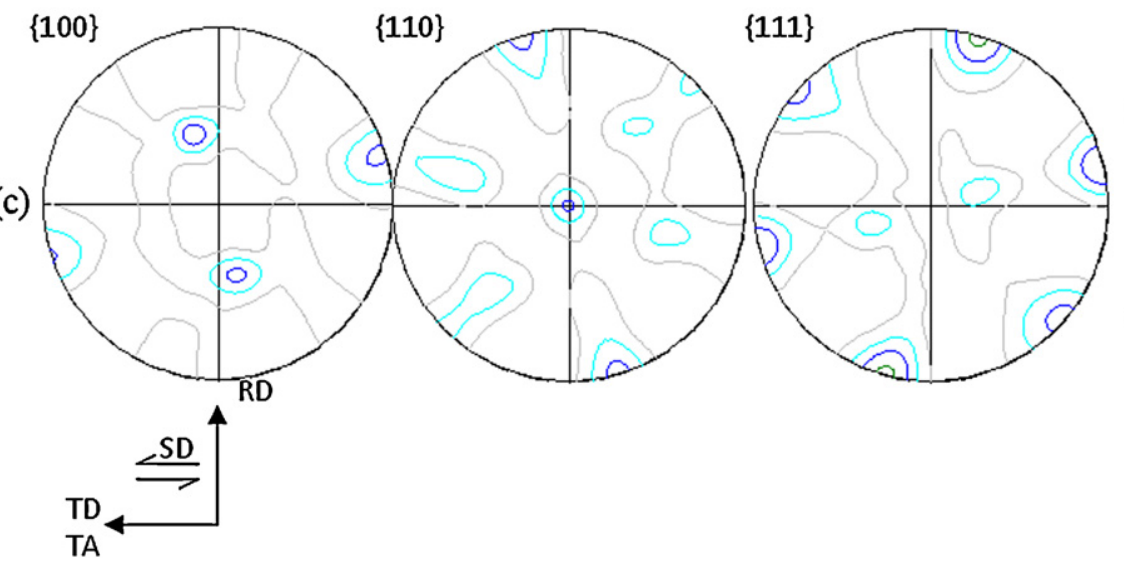
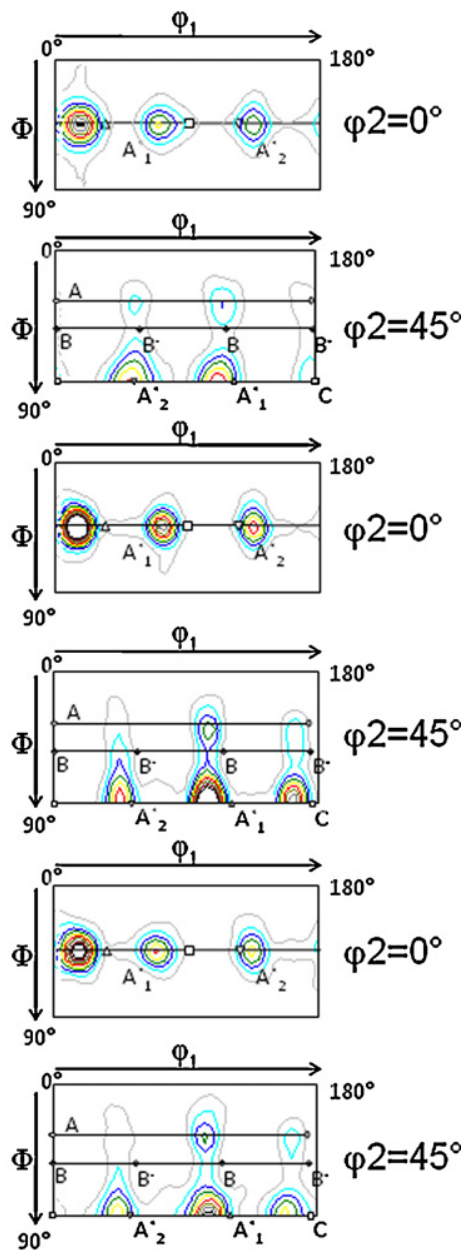

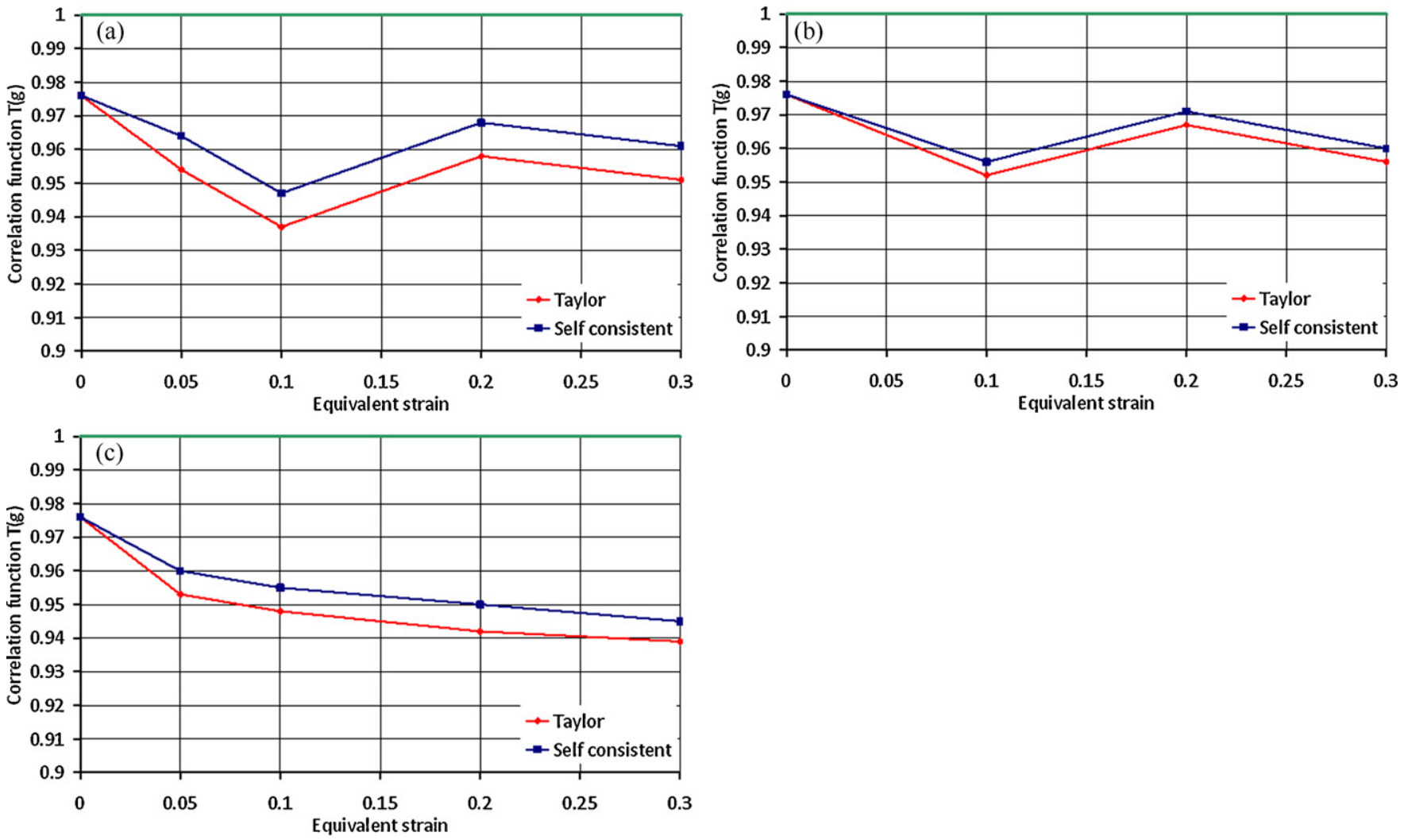

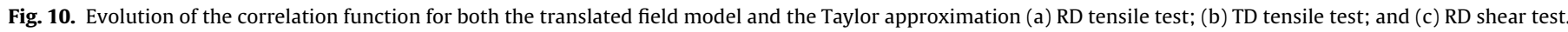

the Taylor assumption, the stress is over estimated during all the deformation, as expected.

The model is then used to simulate the tensile test along the TD direction and the shear test along the RD direction (Fig. 6b and c). Because the initial texture is very smooth, the material does not exhibit a strong mechanical anisotropy between the TD and the RD direction. Again, the Taylor assumption results in an over estimation of the stress. The predicted equivalent stress-strain response of the material in simple shear is found very close to the RD and TD tension stress-strain responses though the flow stress is slightly lower as in the experiments.Texture evolution

The initial texture is quasi-isotropic with a rather low Texture Index $=1.23$ (Fig. 5). However we can distinguish two smooth component: $\{110\}<001>$ Goss and $\{112\}\langle 111\rangle$ Copper, with, respectively, an intensity of 2.9 and 1.5 . The stable orientations for fcc metals obtained during tension $[26,40]$ and shear deformation $[41,42]$ for metals deforming by slip alone are presented in Fig. $5 \mathrm{a}$ and $\mathrm{b}$.

The predicted textures for the three mechanical tests (RD tensile test, TD tensile test and RD shear test) are represented, respectively, in Figs. 7-9. All the textures are given for an equivalent strain of 0.3. The experimental texture is given in (a), the textures predicted by the translated field model and the Taylor model are shown in (b) and (c), respectively. For the tensile tests, the $\varphi_{2}=45^{\circ}$ ODF section is represented using orthorhombic symmetry. In the case of the shear deformation, the monoclinic symmetry is applied.

RD uniaxial tension leads to a sharp texture characterized by two fibers, the $\langle 111\rangle / / R D$ and the $\langle 100\rangle / /$ RD (Fig. 7a). The developed ideal orientations in the $\varphi_{2}=45^{\circ} \mathrm{ODF}$ section and assuming deformation by slip alone are the Rotated Brass, Copper, Goss and Cube, with intensities of 7.8, 7.1,6.8 and 1.3, respectively. Both scale transitions give the same trend and reproduce well the $\langle 111\rangle / / \mathrm{RD}$ and $\langle 100\rangle / /$ RD fibers. But the Taylor scale transition underestimates a little the texture. The intensities of the Rotated Brass, Copper, Goss and Cube are, respectively, 6.5, 5.2, 5.7 and 1.7 for the Taylor case (Fig. 7c) and 7.5, 5.9, 6.7 and 1.9 for the translated field model (Fig. 7b), which is closer from the experimental values.

Fig. 8 the experimental and predicted textures for the TD tensile test. The experimental texture is again very sharp, with the development of the $\langle 111\rangle / /$ TD and $\langle 100\rangle / /$ TD fibers, with the Brass, Rotated Copper, Rotated Goss and Cube orientations (the values of the intensities are, respectively, 9.15, 4, 1.65 and 1.3). Again, both scale transitions reproduce with a good accuracy the two fibers and the four ideal orientations. The Brass orientation is slightly over estimated in the case of the translated field model, with an intensity of 10.2 ( 9.15 for the experimental value). The other intensities are well reproduced.

The experimental and predicted textures for the simple shear test are presented in Fig. 9. The equivalent strain is equal to 0.3, corresponding to a shear strain $\gamma=0.6$. As we can see on the two ODF sections $\left(\varphi_{2}=0^{\circ}\right.$ and $\left.\varphi_{2}=45^{\circ}\right)$ of the experimental texture, the ideal orientations (presented in Fig. 5) are not reached at this deformation step because of the untimely rupture of the specimen. $A^{*} 1$ and $A^{*} 2$ intensities were found similar over the deformation whereas $C$ intensity remains low. Small orientation densities close to $A / \bar{A}$ and $B / B^{-}$were also observed. Pole figures indicate that $\{111\}$ planes gradually become parallel to the plane of the imposed shear deformation on the sample. Besides, the $\langle 110\rangle$ direction gradually becomes parallel to the shear direction. Simple shear tests on high-SFE fcc metals that deform by slip alone promote $A^{*} 1$ and $C$ orientations [43]. Beyerlein and Tóth [44] found that silver (low SFE) submitted to ECAE displayed a low $A^{*} 1$ orientation but a high $A^{*} 2$ orientation. They attributed these results to deformation twinning since induced twins belong to $A^{*} 2$ orientations. In our work, the twin volume fraction produced in $\mathrm{Fe}-22 \mathrm{Mn}-0.6 \mathrm{C}$ remains lower than $10 \%$ (see Section 4.1 ) and so it is not high enough to increase 

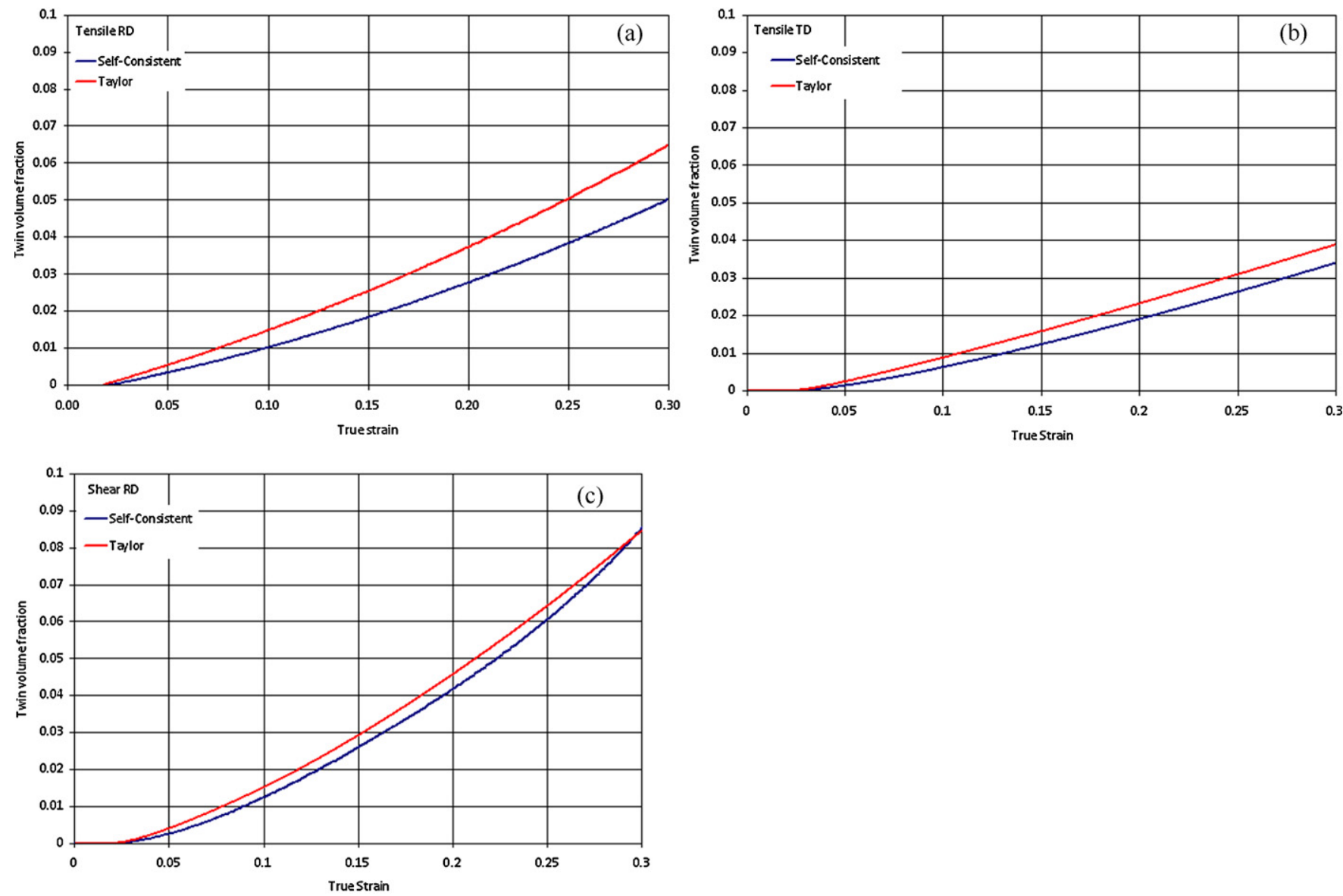

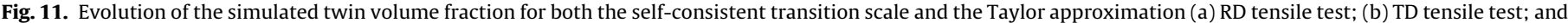
(c) RD shear test.

significantly the $A^{*} 2$ intensity. Concerning modeling, the same shift between the predicted orientations and the ideal ones is observed. The components close to the $A^{*} 1, C$ and $A^{*} 2$ orientations are well reproduced by both scale transitions, but their intensities are over estimated.

The good agreement between the experimental and simulated textures is verified at all the deformation steps. This is shown in Fig. 10, where the evolution of the correlation function (see Eq. (1)) is plotted against the equivalent strain, for each test. The correlation function determines the correspondence between the experimental and simulated textures. If the two textures perfectly correspond, the value of the correlation function is equal to 1 . For the uniaxial tensile and the shear tests, and for both scale transitions, the correlation function remains close to 1 during all the deformation. The translated field model always fit better the experimental texture than the Taylor one. As the beginning of the macroscopic stress-strain curves is not well fitted, the correlation function decreases a little (up to 0.95-0.94). In all cases, the predicted textures are in good agreement with the experimental ones. Since modeling does not take into account texture due to twinning, these results demonstrate that the texture of deformed $\mathrm{Fe}-22 \mathrm{Mn}-0.6 \mathrm{C}$ is slip-dominated. This result is expected since the twin volume fraction remains low $(<10 \%)$.

\subsection{Twinning kinetics}

Fig. 11a-c presents the evolution of the predicted twin volume fraction with the deformation. Few experimental data are available to compare with the predicted results. But it can be assumed that the twin volume fraction remains below $10 \%$ at fracture of the sample $\left(\varepsilon_{\text {true }}=0.55\right)$, at it is showed in $[8,18]$. As expected, the twinning volume fraction starts to increase at $\varepsilon_{\text {eq }}=0.02$ (the critical shear stress for twinning $\tau_{c}^{t w(h)}$ was adjusted to get this result in good agreement with experiments). The analyzes of EBSD measurements have showed that (i) the twin volume fraction is higher for the RD uniaxial tension than for the TD case (ii) the simple shear test produces a higher twin volume fraction than in the uniaxial tensile tests. As the Taylor assumption overestimates the stress level, the resulting twin volume fraction is higher than for the translated field model prediction. Anyway, the predicted volume fractions with both scale transitions are in good agreement with the experimental features (i) $5 \%$ (translated field model) for the RD tension simulation; (ii) 3.5\% for the TD tension simulation; and (iii) $8.5 \%$ for the shear simulation at 0.3 strain. The predicted twin volume fraction increases with strain and does not exhibit any saturation whatever the loading path. Other works achieved on low stacking fault energy fcc metals such as $\alpha$-brass [45] showed a saturating production of deformation twinning but at larger strains $(>0.3)$ and larger twin volume fractions $(>0.3)$. In our works, testing does not permit to attain such large strains because of the fracture of the specimens.

The evolutions of the twinning activity with the deformation are plotted in Fig. 12 from a to c, corresponding, respectively, to the RD tensile test, TD tensile test and RD simple shear test. In each case, twinning is activated in the earlier stages of deformation $\left(\varepsilon_{\text {eq }}=0.02\right)$, resulting to a fast decrease of the grain proportion having no activated twinning system. Fig. 12 shows that RD uniaxial tension promotes twinning in $90 \%$ of grains and $30 \%$ of grains have two active twin systems at $0.07-0.08$ strain. In contrast, RD simple 

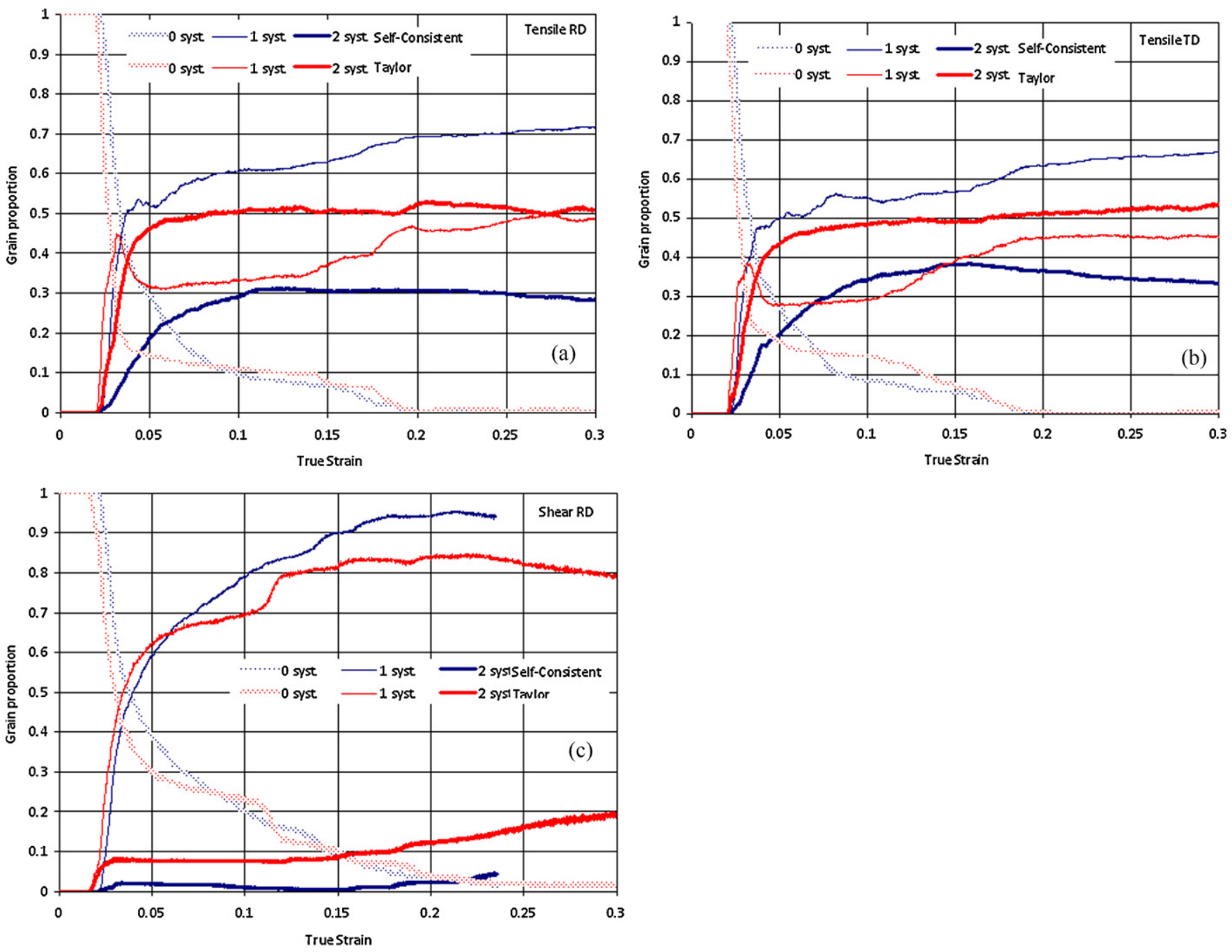

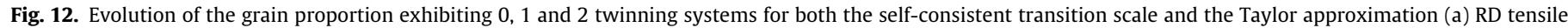
test; (b) TD tensile test; and (c) RD shear test.

shear promotes twinning in $70 \%$ of grains. Besides, only one twin system is active in those grains. These predicted microstructural features are in good agreement with experimental observations and are closely related to the polycrystal texture. Indeed, we checked that grains belonging to the $\langle 111\rangle / /$ RD orientation which develops under RD and TD uniaxial tensions are well-oriented to activate more than one twin systems. On the opposite, grains belonging to $A^{*} 1$ orientation which develops under simple shear are well-oriented to activate one single twin system. The small discrepancies between RD and TD tension results are attributed to the slight initial texture of the polycrystal.

In addition, twin-twin interactions inhibit the twinning activity and so reduce the twin volume fraction rate. Indeed, in good agreement with Shiekhelsouk et al. [15], we found that the model predicts an increase of the critical shear stress of the primary twin system in grains having two twin active systems (see Eq. (13)). As a result, RD simple shear which promotes single twinning leads to a higher volume fraction than uniaxial tensions.

To analyze the predicted effect of twinning on the Hall-Petch dynamic effect, we sketched the predicted macroscopic dislocation Mean Free Path (MFP) Lg-tw due only to grain and twin boundaries, the predicted MFP Lro due only to dislocation forest and the complete MFP Ltotal (Fig. 13a-c). These three MFP are averages calculated over the Representative Volume Element as proposed by [27] and used by [15]. The $X$-axes for the graphs in Figs. 11-13 were scaled identically to show the correlation between the MFP and the deformation twinning activity. The decrease of the MFP due to dislocation forest evolution is identical for RD tension and simple shear. However, as soon as twins appear (Fig. 11), an additional decrease due to twinning is predicted: twins act as new barriers to dislocation motion giving rise to the dynamic Hall-Petch effect. This additional effect is stronger for RD simple shear than for RD uniaxial tension. This faster MFP reduction is related to a higher predicted twin volume fraction for RD simple shear than for RD uniaxial tension. From the responses of MP35N low-SFE fcc metals submitted to simple shear and compression, El-Danaf et al. [46] suggest that deformation twins are mainly coplanar with the active slip system in shear deformation mode on the contrary to compression mode. From the modeling point of view, we checked that the primary twin system was non-coplanar to at least one active slip system. Actually, for all the loading paths studied, the predicted deformation is dominated by multi-slip at the onset of twinning and the twin systems are non-coplanar to at least one active slip system. Consequently, twins really act as barriers to dislocation motion as soon as they appear. The larger twin volume fraction, the faster reduction in MFP. 

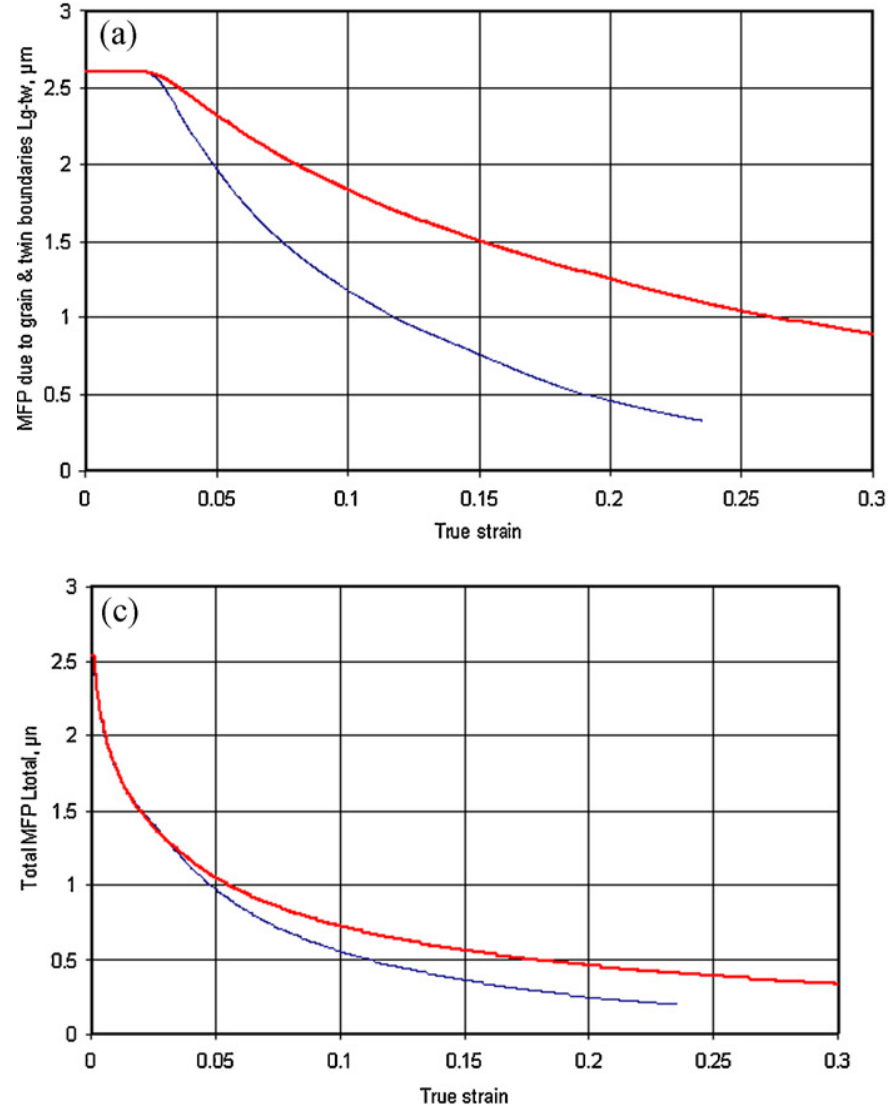

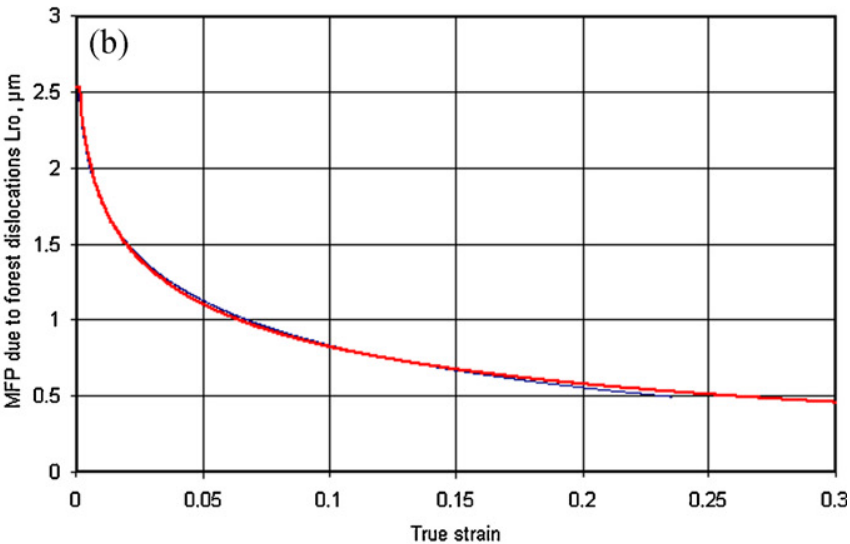

— Shear RD — Tension RD

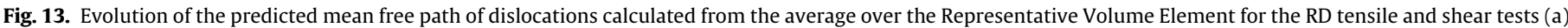
MFP due to grain and twin boundaries Lg-tw; (b) MFP due to forest dislocations Lro; and (c) total MFP.

\section{Conclusion}

We analyzed the effect of monotonous loading path on texture, deformation twinning and stress-strain response of polycrystalline high Mn TWIP steel. Experimental data were compared to predicted results obtained by two polycrystalline models. These two models are based on the same single crystal constitutive equations but differ from the homogenization scheme. The translated field model, inspired from the self-consistent approximation, was used to fit the model parameters. As expected, the translated field model predicts the texture, the twinning activity and stress-strain response for all the studied loading paths in better agreement with experiments than the Taylor model. However, the two homogenization scheme predicts the same qualitative trends. Besides, they assessed that the texture is mainly controlled by the crystallographic slip.

At the onset of plasticity, multi-slip dominates the deformation and the strain hardening. We observed a predicted reduction of the overall dislocation MFP correlated with the evolution of dislocation densities which is similar for all the studied loading paths. Despite these similarities, the texture and its evolutions strongly depend on the loading path and is responsible for the anisotropy in deformation twinning. RD and TD uniaxial tensions and RD simple shear induce twinning in most of the grains. The initial texture is smooth and displays grain well-oriented for twinning whatever the loading path. In addition, texture development increases the number of grains well-oriented for twinning for all the loading paths. However, uniaxial tensions favor multi-twinning in $30 \%$ of grains at the small strain regime whereas RD simple shear favors single twinning. Twin-twin intersections increase the difficulty of producing new twins. As a result, the twin production rate and so the twin volume fraction are higher for RD simple shear than for uniaxial tensions. As the primary twin system is non-coplanar to at least one active slip system whatever the loading path, twins act as new barriers to dislocation motion as soon as they appear and reduce the dislocation MFP, leading to the dynamic Hall-Petch effect. The MFP reduction is responsible for the high strain hardening of such materials. However, twin-twin intersections, intragranular stresses induced by twinning and dislocation structures play also a role. Further investigations are required to better understand the relationships between induced microstructure, internal stresses and strain hardening in Fe-22Mn-0.6C.

\section{References}

[1] O. Bouaziz, S. Allain, C.P. Scott, P. Cugy, D. Barbier, Current Opinion in Solid State and Materials Science 15 (2011) 141-168.

[2] O. Grässel, L. Krüger, G. Frommeyer, L.W. Meyer, International Journal of Plasticity 16 (2000) 1391-1409.

[3] C. Scott, S. Allain, M. Faral, N. Guelton, Revue De Metallurgie: Cahiers D Informations Techniques 103 (2006) 293-302.

[4] I. Karaman, H. Sehitoglu, A.J. Beaudoin, Y.I. Chumlyakov, H.J. Maier, C.N. Tome, Acta Materialia 48 (2000) 2031-2047.

[5] L. Remy, Acta Metallurgica 26 (1978) 443-451.

[6] I. Gutierrez-Urrutia, S. Zaefferer, D. Raabe, Materials Science and Engineering A 527 (2010) 3552-3560.

[7] R. Ueji, N. Tsuchida, D. Terada, N. Tsuji, Y. Tanaka, A. Takemura, K. Kunishige, Scripta Materialia 59 (2008) 963-966.

[8] D. Barbier, N. Gey, S. Allain, N. Bozzolo, M. Humbert, Materials Science and Engineering A: Structural Materials Properties Microstructure and Processing 500 (2009) 196-206.

[9] D. Barbier, N. Gey, N. Bozzolo, S. Allain, M. Humbert, Journal of Microscopy: Oxford 235 (2009) 67-78.

[10] L. Meng, P. Yang, Q. Xie, H. Ding, Z. Tang, Scripta Materialia 56 (2007) 931934.

[11] P. Yang, Q. Xie, L. Meng, H. Ding, Z. Tang, Scripta Materialia 55 (2006) 629-631.

[12] A. Staroselsky, L. Anand, Journal of the Mechanics and Physics of Solids 46 (1998) 671. 
[13] S.R. Kalidindi, International Journal of Plasticity 17 (2001) 837-860.

[14] M. Cherkaoui, 1st International Conference on Multiscale Materials Modelling (MMM), London, England, 2002, pp. 3945-3958.

[15] M.N. Shiekhelsouk, V. Favier, K. Inal, M. Cherkaoui, International Journal of Plasticity 25 (2009) 105-133.

[16] O. Bouaziz, S. Allain, C. Scott, Scripta Materialia 58 (2008) 484-487.

[17] O. Bouaziz, N. Guelton, Materials Science and Engineering A 319-321 (2001) $246-249$.

[18] A. Soulami, K.S. Choi, Y.F. Shen, W.N. Liu, X. Sun, M.A. Khaleel, Materials Science and Engineering A 528 (2011) 1402-1408.

[19] G. Dini, R. Ueji, A. Najafizadeh, S.M. Monir-Vaghefi, Materials Science and Engineering A 527 (2010) 2759-2763.

[20] G.I. Taylor, Journal of the Institute of Metals 62 (1938) 307-324.

21] H. Sabar, M. Berveiller, V. Favier, S. Berbenni, International Journal of Solids and Structures 39 (2002) 3257-3276.

[22] S. Allain, J.P. Chateau, O. Bouaziz, S. Migot, N. Guelton, Materials Science and Engineering A 387-389 (2004) 158-162.

[23] P. Flores, P. Moureaux, A.M. Habraken, Advances in Experimental Mechanics IV, 2005, pp. 91-97.

[24] R. Hill, Proceedings of the Royal Society of London Series A: Mathematical and Physical Sciences 193 (1948) 281-297.

[25] D. Barbier, A. Bolle, J.J. Fundenberger, C. Laruelle, A. Tidu, Materials Processing and Texture, 2009, pp. 87-93.

[26] H.J. Bunge, Texture Analysis in Material Science, Butterworth Publication, London, 1982

[27] S. Allain, J.P. Chateau, O. Bouaziz, Materials Science and Engineering A 387-389 (2004) 143-147.

[28] S.R. Kalidindi, International Journal of Plasticity 14 (1998) 1265-1277.
[29] S. Berbenni, V. Favier, X. Lemoine, A.B. Berveiller, Materials Science and Engineering A: Structural Materials Properties Microstructure and Processing 372 (2004) 128-136.

[30] P. Franciosi, Acta Metallurgica 33 (1985) 1601-1612.

[31] U.F. Kocks, H. Mecking, Progress in Materials Science 48 (2003) 171-273.

[32] G. Proust, C.N. Tome, G.C. Kaschner, Acta Materialia 55 (2007) 2137-2148.

[33] H.J. Bunge, R. Fuchs, Physica Status Solidi 32 (1969) 169.

[34] S. Ahzi, Ph.D. Thesis, University of Metz, France, 1987.

[35] P. Van Houtte, Acta Metallurgica 26 (1978) 591-604.

[36] A.A. Salem, S.R. Kalidindi, S.L. Semiatin, Acta Materialia 53 (2005) 3495-3502.

[37] L.J. Collet, F. Bley, A.M. Deschamps, H. De, F.J. Berar, C. Scott, The Deformation Mechanisms of TWIP Steels (Fe-Mn-C) Viewed by X-ray Diffraction, Trans Tech Publications, Zurich, SUISSE, 2007.

[38] U.F. Kocks, A.S. Argon, M.F. Ashby, Progress in Materials Science 19 (1975) $1-281$.

[39] H.J. Frost, M.F. Ashby, Deformation Mechanism Maps, Pergamon Press, Oxford, 1982.

[40] J. Hirsch, K. Lucke, Acta Metallurgica 36 (1988) 2863-2882.

[41] F. Montheillet, M. Cohen, J.J. Jonas, Acta Metallurgica 32 (1984) 2077-2089.

[42] L.S. Tóth, K.W. Neale, J.J. Jonas, Acta Metallurgica 37 (1989) 2197-2210.

[43] L.S. Tóth, R. Arruffat Massion, L. Germain, S.C. Baik, S. Suwas, Acta Materialia 52 (2004) 1885-1898.

[44] I.J. Beyerlein, L.S. Tóth, Progress in Materials Science 54 (2009) 427-510.

[45] S. Asgari, E. ElDanaf, S.R. Kalidindi, R.D. Doherty, Metallurgical and Materials Transactions A: Physical Metallurgy and Materials Science 28 (1997) 1781-1795.

[46] E. El-Danaf, S.R. Kalidindi, R.D. Doherty, International Journal of Plasticity 17 (2001) 1245-1265. 